\title{
Fatores, inovações e impactos do maior acordo de paz da América Latina
}

\author{
Factores, innovaciones e impactos del mayor acuerdo de paz en América \\ Latina \\ Factors, innovations and impacts of the largest peace agreement in Latin \\ America
}

\author{
Bel. Luciano Alexandrino dos Santos Junior ${ }^{1}$ \\ Dr. José Blanes Sala²
}

\begin{abstract}
Resumo
O Acordo de Paz celebrado em 2016 pelo Estado colombiano e as Forças Armadas Revolucionárias da Colômbia (FARC) abrangeu a reforma de problemas estruturais como reforma rural, participação política, vítimas e drogas ilícitas. Considerando seus fatores e atores questiona-se quais seriam as características que o diferencia da tentativa anterior e quais fatores impulsionaram ambos os lados a buscar a negociação. Tal indagação norteou este estudo e para respondê-la utilizou-se o método comparativo de sistemas similares e o levantamento bibliográfico. Parte-se da hipótese que existe um conjunto de motivações tanto das FARC como do Estado para buscar a paz ao invés do enfrentamento armado, tais como desgaste do aparato militar e geoestratégico da guerrilha, reduzido com as políticas de segurança democrática de Álvaro Uribe, entre outros fatores. Dessa forma, o acordo de paz é uma oportunidade para a Colômbia e para o mundo construir uma sociedade embasada na paz e no diálogo, pois, experimentou as mais violentas experiências e a comprovação de que a guerra e as armas são ineficazes para promover o desenvolvimento social e a solução de problemas estruturais negligenciados historicamente pelo Estado.
\end{abstract}

Palavras-Chave: Acordo de Paz; Inovações; Motivações; Colômbia; FARC.

\section{Resumen}

El Acuerdo de Paz firmado en 2016 por el Estado colombiano y las Fuerzas Armadas Revolucionarias de Colombia (FARC) cubrió la reforma de problemas estructurales como la reforma rural, la participación política, las víctimas y las drogas ilícitas. Teniendo en cuenta sus factores y actores, se cuestiona cuáles serían las características que lo diferencian del intento anterior y qué factores llevaron a ambas partes a buscar negociaciones. Esta pregunta guió este estudio y para responderlo, utilizamos el método comparativo de sistemas similares y la encuesta bibliográfica. Se asume que existe un conjunto de motivaciones para que las FARC y el Estado busquen la paz en lugar de la confrontación armada, como el desgaste del aparato militar y geoestratégico de la guerrilla, reducido por las políticas de seguridad democrática de Álvaro Uribe, entre otros factores. Por lo tanto, el acuerdo de paz es una oportunidad para que Colombia y el mundo construyan una sociedad basada en la paz y el diálogo, ya que ha experimentado las experiencias más violentas y la prueba de que la guerra y las armas no son efectivas para promover el desarrollo y la solución de problemas estructurales históricamente descuidados por el Estado.

Palabras claves: Acuerdo de paz; Innovaciones; Motivaciones; Colombia; FARC.

\footnotetext{
1 (Mestrando em Ciências Humanas e Sociais; Universidade Federal do ABC; Santo André, SP, Brasil; luciano.alexandrinojr@gmail.com)

2 (Doutor em Direito Internacional; Universidade Federal do ABC; Santo André, SP, Brasil; blanes@ufabc.edu.br)
} 


\begin{abstract}
The Peace Agreement signed in 2016 by the Colombian State and the Revolutionary Armed Forces of Colombia (FARC) covered the reform of structural problems such as rural reform, political participation, victims and illicit drugs. Considering its factors and actors, it is questioned what are the characteristics that differentiate it from the previous attempts and which factors drove both sides to seek negotiation. This question guided this study and to answer it, we used the comparative method of similar systems and the bibliographic survey. It is assumed that there is a set of motivations for both the FARC and the State to seek peace instead of armed confrontation, such as wearing down the guerrilla's military and geostrategic apparatus, reduced by the democratic security policies of Álvaro Uribe, among others factors. Thus, the peace agreement is an opportunity for Colombia and the world to build a society based on peace and dialogue, as it has experienced the most violent scenarios and the proof that war and weapons are ineffective to promote development and the solution of structural problems historically neglected by the State.
\end{abstract}

Keywords: Peace agreement; Innovations; Motivations; Colombia; FARC.

\title{
1. Introdução
}

O conflito armado entre o Estado nacional da Colômbia e as Forças Armadas Revolucionárias da Colômbia (FARC) tornou-se o conflito armado mais sangrento e longo da América Latina e do mundo (BBC, 2016) reverberando para os países vizinhos, interferindo em certa medida nas relações internacionais e vivenciando a ingerência dos interesses de atores externos. Após décadas de negociações e tentativas de um acordo de paz fracassados o governo finalmente concretizou um acordo final de paz em 2016 liderado pelo então mandatário Juan Manoel Santos (2010-2018).

Os primeiros indícios de negociação de paz do governo com as forças insurgentes começaram em 1980. Nesta, um dos acordos seria a formação de um partido político, a União Patriótica (UP) que posteriormente viria a fracassar na tentativa de representá-los oficialmente (SILVEIRA, 2014). O governo justificou o fracasso culpando a guerrilha de usar essa tentativa de firmar a paz para se fortalecer militarmente. Em contrapartida, as guerrilhas acusavam a ineficiência do governo de reintegrar os ex-guerrilheiros na sociedade e de protegê-los, pois, após a dissolução da guerrilha M-19 os ex-combatentes foram perseguidos e assassinados. Este fato marcou uma profunda desconfiança em qualquer outra iniciativa de acordo para a paz.

Segundo Antunes (2018) a segunda tentativa de negociação da paz ocorreu em 1998, o presidente Andrés Pastrana (1998-2002) destinou à guerrilha uma área desmilitarizada ao sul do país para iniciar o fim dos combates armados, mas tal iniciativa não funcionou devido a negativa do governo para a liberação de guerrilheiros das FARC ao narcotráfico e a pressão exterior, principalmente dos EUA, seus desdobramentos impediram a consecução da paz nacional. 
Anos mais tarde, baseado nos insucessos de acordos anteriores e com uma nova postura securitária, o governo de Álvaro Uribe (2002- 2010) impôs uma política de forte enfrentamento armado direto. Com isso, as forças militares das FARC diminuíram consideravelmente e as ações do governo, mesmo que violentas, satisfizeram a vontade popular (SILVEIRA, 2014). Após o 11 de setembro de 2001 surge o conceito de "terrorismo" nas Relações Internacionais, definição esta que se enquadrou aos membros das FARC. Portanto, a partir do entendimento de que as FARC era um grupo terrorista, nota-se a perda de parte do apoio popular e intelectual, devido à repercussão dos sequestros e assassinatos noticiados na comunidade internacional, marcada pela campanha antiterrorista mundial liderada pelos EUA (PECÁULT, 2010).

Em um contexto internacional comparado com outros conflitos e guerras civis com altos índices de vítimas da sociedade civil o conflito colombiano está a frente com aproximadamente sete milhões de vítimas do conflito, diante de países como o Sudão que teve mais de duzentos mil mortos pelo conflito interno desde 2014, da Serra Leoa com cerca de cento e vinte mil mortos e quinhentos mil refugiados por conta da guerra civil (19912002) e ainda Ruanda com o genocídio de 1994 com cerca de oitocentos mil mortes (ALTO COMISSARIADO PARA A PAZ, 2017).

Diante desse complexo cenário e após a morte de milhares de vítimas, uma cultura de violência alastrou-se pelo país, desacreditando qualquer processo de paz. Contudo, após um longo processo de negociação, disputas, conflitos e cooperação, o país consolidou um acordo efetivo e um definitivo cessar fogo com um amplo apoio da comunidade internacional como a União Europeia (UE), Organização dos Estados Americanos (OEA), Organização das Nações Unidas (ONU) e dos Estados Unidos da América (EUA), visando um cessar-fogo e uma paz estável.

O primeiro passo do largo processo de negociação do acordo de paz foi a etapa secreta exploratória de março de 2011 a fevereiro de 2012, para verificar a disposição e interesse da guerrilha em realizá-la. Tratava-se de um cenário de insegurança e instabilidade por parte dos negociadores representantes dos políticos no país, dentre outras atividades. Não obstante, em meio à absoluta confidencialidade identificaram o interesse nos líderes guerrilheiros em estabelecer um fim a esse conflito histórico por meio do diálogo, nessa ocasião acordaram que as negociações ocorreriam em Havana, Cuba, um país que garantiria e proporcionaria confiança, confidencialidade e neutralidade (SANTOS, 2019).

O governo e as FARC acordaram que o processo de paz ocorreria por meio de três fases: preparação, término do conflito e transformação do conflito. Na fase preliminar (2011- 
2012) as partes discutiram a agenda e metodologia para os encontros e diálogos, que resultaram no acordo global para a terminação do conflito armado, em agosto de 2012, dois meses depois iniciaram as negociações formais. A sessão inaugural ocorreu em Oslo, e ali definiu-se que o desenvolvimento das próximas etapas seria em Havana, Cuba. Neste acordo firmado na etapa exploratória estabelecia que o propósito dos diálogos de paz entre governo e FARC que aconteceriam em Havana era para terminar o conflito armado, enfatizando que a terceira fase do processo de paz seria no próprio solo colombiano e envolveria toda a sociedade.

Segundo Santos (2019) as partes acordaram uma agenda de trabalho intensa e contínua, ocorreram onze reuniões em Havana com um curto período de intervalo entre elas com consultas e preparações para as próximas rodadas de negociações. Após cada rodada, as equipes negociadoras deveriam elaborar relatórios para apresentar ao público o conteúdo que foi negociado e quais medidas foram adotadas descrevendo-as minuciosamente. Cada lado poderia nomear dez delegados, em que cinco deles seriam plenipotenciários, auxiliados por uma equipe maior de no máximo vinte pessoas.

A delegação das FARC foi composta por combatentes, liderados pelo segundo maior líder-geral, Iván Marquez. A delegação foi alojada em uma área residencial fornecida pelo governo cubano próximo ao hotel onde as negociações ocorreram. Com o progressivo avanço das negociações as FARC modificaram alguns de seus comandantes para expressar a rotatividade e representatividade de todo grupo e, também, para oferecer um retorno para seus membros sobre o desenvolvimento dos encontros em Havana.

A delegação do governo foi cuidadosamente selecionada para garantir o compromisso de representar o setor privado e militar da sociedade: um general retirado das forças armadas e um da polícia nacional, contava também com um proeminente líder empresário acompanhado do chefe negociador Humberto de la Calle, além do especialista em estudos sobre paz, Sérgio Jaramillo (SANTOS, 2019).

Ainda nas etapas iniciais, as partes adotaram uma regra em comum durante o período de negociações em que "nada seria acordado até que tudo fosse acordado" (SANTOS, 2019, p. 17) para permiti-los possuir uma flexibilidade para se ajustar às mudanças circunstanciais que resultariam das negociações, especialmente no que se referia ao cessar fogo, em que este só seria formalmente aplicado com a assinatura e implementação de um acordo final. $\mathrm{O}$ governo inequivocamente insistiu nesse ponto para demonstrar à opinião pública e à FARC que mesmo em meio aos diálogos de paz o Estado possuía autonomia e força política e militar, exercendo seu papel de garantir a segurança pública (HERBOLZHEIMER, 2016). 
Assim, a partir da análise bibliográfica preliminar sobre o processo de paz colombiano e o método de análise comparativa entre acordos de paz anteriores, a seguir, pretende-se apresentar cinco pontos principais de inovações do acordo de paz firmado em 2016, apontados por Herbolzheimer $(2016)^{3}$ para ao final deste artigo refletir-se sobre como tais inovações contribuíram para a assinatura do acordo final, mesmo em meio à um processo de negociação desafiador e longo.

\section{Mudando a estratégia de luta: motivações para a negociação}

Não foram poucas as tentativas de uma paz negociada entre o governo e as FARC, cabendo-se dessa forma indagar o que os motivou para mais uma vez sentar e dialogar sobre meios pacíficos de solucionar as controvérsias. Conforme Herbolzheimer (2016) existem alguns fatores que influenciaram as duas partes litigantes a buscar um acordo. $\mathrm{Na}$ ofensiva militar do governo Uribe (2002-2010) ainda que o governo não conseguiu derrotar o grupo guerrilheiro, reduziu consideravelmente suas capacidades ofensivas e limitou sua esfera de atuação geograficamente para áreas distantes. Desde sua fundação as FARC sempre se orgulhou de sua habilidade de resistir à formidável ofensiva do poder militar do Estado, mas perceberam que não conseguiriam conquistar o objetivo principal: uma vitória militar contra o Estado (HERBOLZHEIMER, 2016).

Em Paralelo, considerando um contexto regional comparado aos países vizinhos, líderes de esquerda chegavam à presidência "por meio da cédula ao invés da bala" (HERBOLZHEIMER, 2016, p. 2) como Evo Morales na Bolívia, Rafael Correa no Equador e Hugo Chaves na Venezuela e ainda mais simbólico, ex-combatentes guerrilheiros como José Mujica no Uruguai e Dilma Rousself no Brasil. Outro fator que influenciou as FARC foi a morte por causas naturais de seu histórico líder Manuel Marulanda (1930-2008) e a emergência de uma nova liderança com uma visão e princípios internos que pudesse assumir o desafio de uma mudança de paradigma no pensamento do movimento.

Diferentes circunstâncias também influenciaram a decisão do governo de voltar para as mesas de negociação. Apesar dos positivos resultados no enfrentamento armado e do

\footnotetext{
${ }^{3} \mathrm{O}$ estudo de Kristian Herbolzheimer (2016) foi publicado na Norwegian Centre for Conflict Resolution (NOREF) instituição norueguesa que auxiliou as equipes do governo nas negociações de paz, com uma vasta gama de publicações e ações de peacebuilding em processos de paz e negociação ao redor do mundo. Tal estudo foi imprescindível para a elaboração da presente pesquisa e configura-se como uma importante ferramenta para qualquer estudioso de resoluções de conflitos e do processo de paz colombiano.
} 
sucesso do governo em transformar grande maioria da opinião pública contra as FARC, uma vitória militar completa sobre o grupo provou ser uma ilusão no governo Uribe. Ademais, a exclusão dos líderes da guerrilha na política poderia se tornar contra produtivo, porque significaria que ramificações das FARC poderiam voltar à luta armada com o intuito de adentrar na política (ANTUNES, 2018). Com isso, o governo adotou uma reforma e agenda moderna que incluía uma normalização diplomática gradual com os países vizinhos Equador e Venezuela, além de reformas estruturais rurais, de participação política e de combate à produção de drogas. Finalmente, também se notou uma pressão moral para prevenir futuras perdas de vidas e a violação dos direitos humanos pelos dois lados do conflito, incluindo o Estado.

Construir um sólido acordo de paz faz surgir mais questões do que respostas, pois "todo processo de paz aprende, em certa medida, com algum ponto ou desenvolvimento de algum outro lugar, mas também inova-se para ajustar-se aos desafios presentes em nível local e considerando o contexto temporal em que se insere" (HERBOLZHEIMER, 2016, p. 2). Assim como apresenta Galtung (1976) para um acordo de paz se tornar efetivo e duradouro é necessário consolidar a paz, analisando de uma forma mais profunda as origens do conflito e a violência estrutural construída socialmente buscando superá-la por meio da promoção de uma paz positiva. Dessa forma, o acordo entre o governo e as FARC incluem diversas características inovadoras se comparadas aos processos de paz anteriores ou outros acordos ao redor do mundo relacionado com a transformação do conflito e não simplesmente seu término.

Nesse sentindo, a partir da abordagem teórica do peacebuilding, infere-se que para a efetiva consolidação da paz é necessário distinguir entre o simples término de um conflito e uma profunda transformação social que está relacionada com as causas históricas do mesmo (GALTUNG, 1976). Este conceito elucida a ideia de que qualquer acordo de paz deve ser inclusivo, minucioso e democrático. Antes de começarem a terceira tentativa dos diálogos formais, ambas as partes cuidadosamente analisaram os erros e acertos dos processos anteriores, tanto na Colômbia como internacionalmente (SANTOS, 2019). Com isso, observou-se que nos processos anteriores os atores dificilmente eram considerados de forma efetiva e formal tanto na elaboração da agenda de negociações como no acordo final, o esquema a seguir demonstra essa integração entre os atores do processo de paz. 


\section{Figura 1- Atores do acordo de paz}

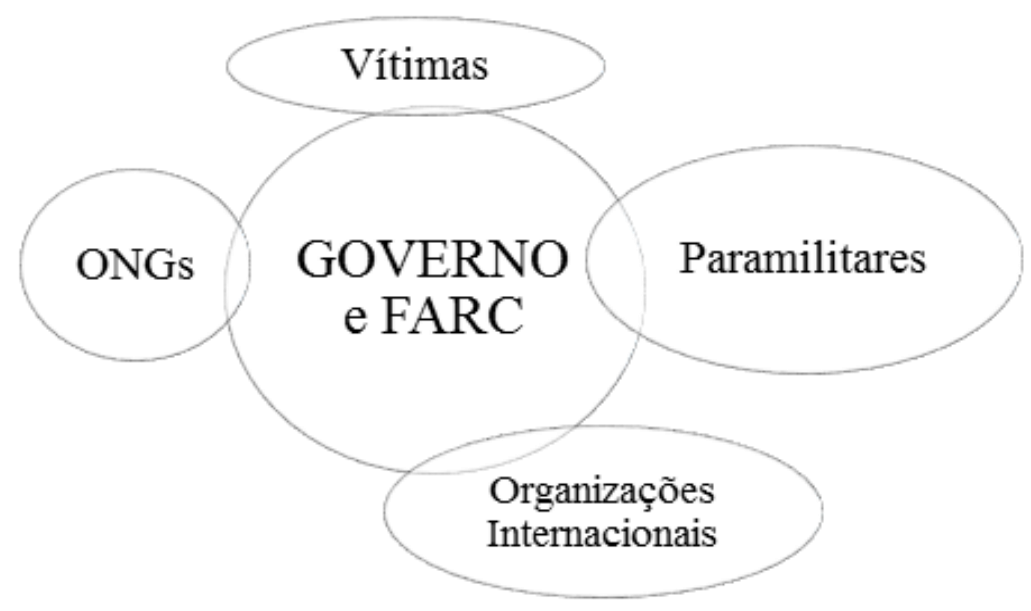

Fonte: Elaboração a partir de dados compilados de CICV (2015) e Antunes (2018).

No centro do processo de paz estão o governo e as FARC, as vítimas, sociedade civil que historicamente mais sofreu com a debilidade estatal nas regiões longínquas e com o conflito armado tanto pelas guerrilhas como pelos paramilitares, as ONGs e organizações internacionais que exerceram um importante papel na reinserção social da guerrilha e na implementação e legitimação da paz (CICV, 2016).

\section{Fim do conflito ou início das transformações? Aprendizados, inovações e avanços}

As duas partes buscaram compreender acertos e erros de tentativas de negociações anteriores, que ultrapassaram o simples cessar fogo para incluírem discussões de problemas históricos que motivaram o início do conflito. A preparação antes da negociação configura-se como uma inovação do processo de paz. A partir de Herbolzheimer (2016) antes da etapa exploratória e ainda em meio aos diálogos em Havana, as equipes negociadoras já estudavam o pós-conflito e todos os principais fatores que sempre empacavam as negociações, pois, como lição de processos anteriores ao redor do mundo a simples assinatura de um acordo não significa necessariamente que a violência cessaria, por isso, estabeleceram uma sólida concepção de distinguir a diferença entre o término do conflito e a transformação dele. A seguir, aponta-se diferentes acepções na elaboração e propósitos das negociações de paz em uma análise comparativa. 


\section{Tabela 1- Diferenças nos propósitos e alcances das duas últimas negociações de paz do Estado com as FARC}

\begin{tabular}{|c|c|c|}
\hline & $\begin{array}{l}\text { Negociações no governo Pastrana } \\
(1990-2002)\end{array}$ & $\begin{array}{l}\text { Negociações no governo } \\
\text { Santos } \\
(2012-2016)\end{array}$ \\
\hline Objetivos & $\begin{array}{l}\text { Transformações políticas, econômicas e sociais } \\
\text { para construir um novo Estado baseado na justiça } \\
\text { social. }\end{array}$ & Colocar um fim no conflito armado. \\
\hline Suposições & $\begin{array}{l}\text { Negociações conduzidas à um acordo que } \\
\text { abrange todas as raízes que causam o conflito. }\end{array}$ & $\begin{array}{l}\text { Negociações terminam com a guerra e inicia-se } \\
\text { uma nova fase que consiga atingir a inclusão, } \\
\text { deliberação transparente e tomada de decisão nas } \\
\text { origens que causam o conflito e desafios adicionais } \\
\text { que se desenvolveram ao longo dos últimos anos. }\end{array}$ \\
\hline Agenda & $\begin{array}{l}\text { Ampla, incluindo economia, legislativo, justiça e } \\
\text { reformas securitárias. }\end{array}$ & $\begin{array}{l}\text { Limitada, com foco na reforma rural e garantia de } \\
\text { participação política. }\end{array}$ \\
\hline Atores & $\begin{array}{l}\text { O governo e as FARC se viam como legítimos } \\
\text { representantes da sociedade. }\end{array}$ & $\begin{array}{l}\text { O Governo e as FARC compreendem a } \\
\text { necessidade de participação pública e tomada de } \\
\text { decisão democrática. }\end{array}$ \\
\hline Cessar-fogo & $\begin{array}{l}\text { Somente nas zonas desmilitarizadas. Violência } \\
\text { aumentou por parte das duas partes durante as } \\
\text { negociações. }\end{array}$ & $\begin{array}{l}\text { Não. As FARC declarou cessar-fogo unilateral e o } \\
\text { governo respondeu com uma diminuição do } \\
\text { enfrentamento direto. Mortes relacionados com o } \\
\text { conflito diminuíram significativamente no início de } \\
2016 \text {. }\end{array}$ \\
\hline $\begin{array}{l}\text { Participação } \\
\text { Pública }\end{array}$ & $\begin{array}{l}\text { Simbólica. As partes organizaram fóruns } \\
\text { públicos, mas as considerações da população não } \\
\text { eram seriamente analisadas e consideradas. }\end{array}$ & $\begin{array}{l}\text { Fundamental, especialmente na fase pós-conflito. } \\
\text { Múltiplos formatos para participação direta e } \\
\text { indireta. }\end{array}$ \\
\hline Papel das vítimas & & $\begin{array}{l}\text { Fundamental na agenda de negociação. As partes } \\
\text { convidaram cinco delegações de vítimas ( } 60 \\
\text { pessoas em geral). }\end{array}$ \\
\hline $\begin{array}{l}\text { Papel das } \\
\text { mulheres }\end{array}$ & $\begin{array}{l}\text { Ausente na agenda de negociações e durante os } \\
\text { diálogos de paz. }\end{array}$ & $\begin{array}{l}\text { Uma subcomissão de gênero convidou três } \\
\text { delegações para organizações de mulheres ( } 18 \text { no } \\
\text { total). }\end{array}$ \\
\hline $\begin{array}{l}\text { Prazos e } \\
\text { Frequência }\end{array}$ & Aberta (estendendo-se ao longo dos anos). & $\begin{array}{l}\text { Urgência para concluir as negociações. Frequentes } \\
\text { e intensas sessões interrompidas por um curto } \\
\text { período para consultas e ajustes. }\end{array}$ \\
\hline Desenvolvimento & $\begin{array}{l}\text { As partes começaram a esbarrar em } \\
\text { procedimentos burocráticos e nunca discutiram a } \\
\text { substância da agenda de negociações. }\end{array}$ & $\begin{array}{l}\text { As partes completaram a agenda que } \\
\text { estabeleceram, ainda que, tomou um tempo maior } \\
\text { do que o inicialmente previsto. }\end{array}$ \\
\hline
\end{tabular}

Fonte: Herbolzheimer (2016, p. 3). Tradução livre. Adaptado.

Colocar as vítimas do conflito armado no centro das negociações foi também uma inovação deste acordo, através da participação efetiva em painéis, delegações, exposições e mecanismos de reparação presentes na Justiça de Transição, além da comissão da verdade e 
aparatos jurídicos de garantia de não repetição. Por exemplo, em meio às negociações finais do acordo de paz 12 vítimas foram cuidadosamente escolhidas para representar todas as vítimas e viajaram até Havana, Cuba. Tal ocasião foi desafiadora, mas vital para a consolidação simbólica da paz ao colocar as vítimas cara a cara com os perpetradores de crimes contra elas. O impacto dessas participações das vítimas foi fortemente percebido para ambos os lados da negociação, mas também para as vítimas, que tiveram o direito à verdade sobre o que ocorreu e garantias de reparação financeira, psicológica, entre outras.

Ainda que a reforma agrária tenha sido uma das causas para guerras civis e o surgimento de movimentos revolucionários em diversos conflitos ao redor do mundo, geralmente tal tema não é amplamente discutido ou sequer incluído em um acordo de paz. Contudo, no acordo de paz da Colômbia tal tema recebeu um tratamento e atenção peculiar se comparado com outras resoluções de conflitos, pois "foi o primeiro acordo entre o governo colombiano e as FARC com qualquer avance político substancial neste tema" (HERBOLZHEIER, 2016, p. 5). Analisando o conteúdo do primeiro ponto que foi discutido, a "reforma rural integral", o Estado assume o compromisso de realizar uma distribuição justa de terra, conceder uma ajuda financeira para pequenos fazendeiros e donos de propriedade rural e promover o amplo desenvolvimento de Estados e municípios com preponderância agroindustrial.

A inovação neste ponto do acordo se reflete justamente em tratar do campo colombiano muito além da reforma rural, mas em um enfoque no desenvolvimento estrutural, social e econômico destas localidades. Nota-se que, ao invés de tratar publicamente o tema com os tradicionais discursos de "reforma agrária", sendo esta expressão muito pouco ou sequer utilizada pelas equipes negociadoras do governo nem por apoiadores do acordo, enfatizou-se a "coexistência entre a comunidade rural e o agronegócio" (HERBOLZHEIMER, 2016, p.5).

Segundo Pécault (2010, p. 70) "a economia da droga alimenta de fato todos os atores armados e está, portanto, bem no coração do conflito" e este também teve atenção especial nos pontos discutidos durante as rodadas de negociação. A Colômbia é a maior exportadora de cocaína do mundo, ao longo dos anos a economia ilegal, um negócio altamente lucrativo para comunidades locais rurais se entrelaçou com o conflito, servindo como financiamento das guerrilhas, paramilitares, narcotráfico, corrupção e deterioração do Estado colombiano (PÉCAULT, 2010). Enquanto as FARC admitiram que protegia, organizava, controlava e aplicava taxas aos fazendeiros produtores de cocaína, o governo acusava a guerrilha de ser o principal cartel de droga no país. Dessa forma, este exigiu que as FARC retornassem ao 
Estado seu aparato financeiro advindo do narcotráfico, bem como seu controle nas áreas de produção de coca. Ademais, criou mecanismos jurídicos e suporte financeiro para a substituição da produção de coca por parte dos fazendeiros que não possuíam outra forma de renda.

Apesar de muitas recomendações e um considerável número de resoluções da ONU enfatizando a importância da participação de mulheres nas negociações de paz e resolução de conflitos, elas dificilmente obtêm um assento nas mesas de negociações ou tampouco são contempladas com cargos de protagonismo nos processos de paz. Porém, na Colômbia criouse uma subcomissão de gêneros para consolidar o acordo e quatro mulheres tiveram um importante papel como membras das delegações nas mesas de negociações. Na equipe negociadora do governo faziam parte a Sra. María Angela Holguín, a Sra. María Paulina Riveros e a Srta. Nigeria Rentería, por parte da delegação das FARC possuiu um assento a Sra. Victoria Sandino (GOBIERNO NACIONAL DE COLÔMBIA, 2017).

Herbolzheimer (2016) aponta que o governo teve que seguir uma significante pressão das organizações de mulheres e em setembro de 2014 o governo e as FARC concordaram em criar uma subcomissão de mulheres, imbuídas da tarefa de revisar todos os documentos relativos aos pontos acordados, garantindo que as mulheres se sentissem contempladas e que os documentos tivessem providências relacionadas ao respeito e direito das mulheres. A comissão foi composta por uma diversidade de mulheres das duas partes e três delegadas internacionais. As mulheres desta subcomissão criaram o primeiro espaço permanente entre a sociedade civil e o setor militar. Por fim, é importante destacar que a Colômbia é provavelmente o primeiro país a incluir direitos da comunidade LGBTQI em uma negociação de paz, além da participação de mulheres representantes de diferentes etnias.

Socialmente, diferente de acordos anteriores o governo promoveu iniciativas sociais significativas por meio da educação para a paz para preparar para a implementação antes mesmo do término das negociações. A legislação em 2015 tornou obrigatório para todas as instituições educacionais públicas e privadas (da pré-escola à escola secundária) ajustar seus currículos "com o propósito de criar e fortalecer uma cultura de paz na Colômbia" (HERBOLZHEIMER, 2016, p. 7). Em paralelo, o governo lançou um processo denominado de "a maior conversa do mundo" para fomentar discussões públicas durante a transição para o cenário pós-conflito.

Por sua vez, as FARC pararam todo o treinamento militar a partir de outubro de 2015, e em vez disso, começou a preparar seus combatentes para a transição da organização para uma política de movimento. O governo também foi muito ativo no Twitter e Facebook, com 
uma transmissão semanal de notícias de televisão e rebatendo críticas feitas pela oposição (HERBOLZHEIMER, 2016, p. 9).

\section{Conclusões}

Diferente da última tentativa de negociação do governo com as FARC no governo de Andrés Pastrana (1990-2002), o acordo de paz firmado na gestão de Juan Manoel Santos (2012-2016) buscou aprender com os erros e equívocos das tentativas anteriores, considerando alguns atores internos e externos como os paramilitares, experiências com negociações de outras guerrilhas, organizações não-governamentais, organizações internacionais e principalmente o papel das vítimas do conflito. Nesse aspecto, nota-se uma nova postura se comparada com outros acordos, de buscar ir muito além do simples término do conflito, mas estabelecer reformas estruturais e dar atenção aos temas que remontam à origem do conflito histórico.

As motivações que foram identificadas ao longo desta pesquisa para que ambas as partes decidissem "trocar os fuzis pelo diálogo" foi a diminuição do aparato militar das FARC causada pela política de enfrentamento direto empregada no governo Uribe (2002-2010), portanto, a percepção da guerrilha de que, não conseguiriam tomar o poder pelas armas, além da influência regional de outros países, que partidos e líderes de esquerda conseguiram chegar ao poder por meios democráticos ao invés da revolução armada. Por parte do Estado notou-se uma forte pressão nacional e internacional para encerrar o conflito, porém sem que houvesse mais mortes, além disso, surgiam constantes acusações de violação dos Direitos Humanos por ambas as partes beligerantes.

O acordo de paz firmado em 2016, além de ter sido o maior acordo de paz da América Latina, com amplos reflexos nas relações internacionais, se caracterizou por algumas inovações em relação aos acordos de paz ao redor do mundo, tanto da perspectiva jurídica, como social e econômica, o que contribuiu veemente com seu êxito, apesar de tantas dificuldades e desafios de uma guerra que durou mais de cinco décadas. Com isso, foram apresentadas cinco principais inovações deste acordo de paz, sendo elas: participação das vítimas, negociações sobre a reforma rural, políticas sobre o narcotráfico, subcomissão de gênero, o protagonismo das mulheres e uma campanha de educação social de cultura de paz para preparar a implementação antes mesmo do término das negociações. 
Dessa forma, com base nas motivações e inovações que configuraram os diálogos de Havana pode-se inferir que os primeiros anos da implementação será a prova real da efetividade do acordo de paz, mais difícil, complexo e desafiador do que o próprio processo de negociação em si. Há uma necessidade de superar a desconfiança, medo, ressentimento e ódio criados por décadas de violência, bem como desafiar o cotidiano violento e individualista, através de políticas públicas que possam sobressair os alarmantes níveis de desigualdade social. Contudo, tal transformação só poderá ser notada em médio e longo prazo, após o período de implementação do acordo, que conforme seu estatuto será um período de quinze anos após a celebração do mesmo.

Um acordo formal não será o fim do processo de paz na Colômbia. Será um marco que indica muito mais do que um possível fim do conflito, mas o início de um processo de transição para lidar com problemas estruturais há muito tempo negligenciados pelo Estado. As dificuldades do processo não são exclusivas deste território, mas comum a muitos países em desenvolvimento, porém as inovações e mecanismos do acordo de paz colombiano podem também levar a inovações adicionais para a resolução de outros conflitos, podendo ainda contribuir para a política global da consolidação da paz.

\section{Referências}

ALTO COMISIONADO PARA LA PAZ. Publicaciones e informaciones sobre el acurdo de paz. 2017. Disponível em:

<http://www.altocomisionadoparalapaz.gov.co/herramientas/Paginas/Todo-lo-que-necesitasaber-sobre-el-proceso-de-paz.aspx>. Acesso em 05 de junho de 2019.

ANTUNES, D. F. B. Capacidades para a Paz: Estudo Comparativo dos processos de paz entre o governo colombiano e as FARC nas gestões Andrés Pastrana (1998-2002) e Juan Manuel Santos (2010-2016). Dissertação de Mestrado em Ciência Política da Universidade Federal do Rio Grande do Sul. Porto Alegre: UFRGS, 2018.

BBC. Cronologia del Processo de Paz. BBC World Service, Londres, fev. 2002. Disponível em: <http://news.bbc.co.uk>. Acesso em: 02 de abril de 2019.

. Como a guerra entre o governo da Colômbia e as Farc começou e por que ela durou mais de 50 anos. Bogotá, agosto de 2016. Disponível em:

<https://www.bbc.com/portuguese/brasil-37181620>. Acesso em 20 de abril de 2019.

COLÔMBIA. Acuerdo Final para la Terminación del Conflicto y la Construcción de Una Paz Estable y Duradera. Bogotá, 24 nov. 2016. Disponível em: 〈https://goo.gl/YbUAIk>. Acesso em: 24 de abril de 2019. 
COMITÊ INTERNACIONAL DA CRUZ VERMELHA. Editorial: Colômbia, para além da paz. Comitê Internacional da Cruz Vermelha (CICV), s. 1., 12 mar. 2015. Disponível em: <https://goo.gl/VQkgnB>. Acesso em: 24 de abril de 2019.

COMITÊ INTERNACIONAL DA CRUZ VERMELHA. Colômbia: dez perguntas sobre acordos de paz, acordos especiais e DIH. Comitê Internacional da Cruz Vermelha (CICV), s. 1., 27 jun. 2016. Disponível em: 〈https://goo.gl/yO7M3s〉. Acesso em: 25 de abril de 2019.

CORTES, G. Colômbia: acordo é ponto de partida, ressalvam especialistas. Jornal online da PUC RIO. Rio de Janeiro, 16 de dez de 2016. Disponível em

$<$ http://jornaldapuc.vrc.pucrio.br/cgi/cgilua.exe/sys/start.htm?infoid=5052\&sid=49>. Acesso em 02 de maio de 2019.

COSOY, N. ¿Por qué empezó y qué pasó en la guerra de más de 50 años que desangró a Colombia? BBC Mundo, Bogotá, 24 ago. 2016. Disponível em: 〈https://goo.gl/3MIfdV〉. Acesso em 25 de abril de 2019.

ECHANDÍA, C. El conflicto armado y las manifestaciones de violencia en las regiones de Colombia. Bogotá: Presidencia de la República, Observatorio de Violencia de la Oficina del Alto Comisionado para la Paz, 1999.

GALTUNG, J. Three Approaches to Peace: Peacekeeping, Peacemaking and Peacebuilding. In GALTUNG, Johan (Ed.) Essays in peace research, vol. 2. Copenhagen: Ejlers, 1976, Capítulo II, p. 282-304.

GOBIERNO NACIONAL DE COLÔMBIA. Publicaciones Todo sobre el Acuerdo. 2017. Disponível em: $<$ http://www.altocomisionadoparalapaz.gov.co/herramientas/Paginas/Todo-loque-necesita-saber-sobre-el-proceso-de-paz.aspx>. Acesso em 03 de março de 2020.

HERBOLZHEIMER, K. Innovations in the Colombian peace process. Norwegian Peacebuilding Resource Centre, 2016. Disponível em: < https://www.cr.org/downloads/NOREF_CR_Report_Colombia\%20Innovations_final.pdf >. Acesso em 25 de julho de 2019.

LOAIZA, A G. L. Negociaciones de paz em Colombia, 1982-2009. Un estado del arte. Medellin: Universidad de Antioquia, 2012.

ONU. Missão de Paz da ONU na Colômbia. 2017. Disponível em: $<$ https://unmc.unmissions.org/documentos>. Acesso em 22 de julho de 2019.

OSPINA, H. C. O terrorismo de Estado na Colômbia. Florianópolis: INSULAR, 2010.

PAGLIARI, G. C. Segurança hemisférica: uma discussão sobre a validade e atualidade de seus mecanismos institucionais. Revista Brasileira de Política Internacional, v. 49, ${ }^{\circ} 1$, 2006, p. 26-42.

PALACIOS, M. Seminario haciendo la paz: reflexiones y perspectivas del proceso de paz en Colombia. Semana.com. 2001. Disponível em:

$<$ http://www.semana.com/nacion/articulo/marcos-palacios-seminario-haciendo-pazreflexiones-perspectivas-del-proceso-paz-colombia-ponencia/45663-3>. Acesso em 25 de abril de 2019. 
PÉCAUT, D. As FARC: uma guerrilha sem fins? Tradução de Ivone Castilho Benedetti. São Paulo, SP: Paz e Terra, 2010.

RIBAS, A. C.; CARVALHO, A. P. L.; RAMINA, L. Processo de paz na Colômbia: uma análise à luz do Direito Internacional Humanitário. Revista da Faculdade de Direito UFPR, Curitiba, PR, Brasil, v. 62, n. 1, jan./abr. 2017, p. 273 - 298. Disponível em:

<http://revistas.ufpr.br/direito/article/view/50863>. Acesso em: 25 de abril de 2019.

SANTOS, J. M. La batalla por la paz. Bogotá: Ediciones Peninsula, 2019.

SANTOS, M. Passado e presente nas relações Colômbia-Estados Unidos: a estratégia de internacionalização do conflito armado colombiano e as diretrizes da política externa norteamericana. Revista Brasileira Política Internacional, 53, 1, p. 67-88, 2010.

SILVEIRA, W. A. As FARC- EP, o Plano Colômbia e seus desdobramentos nas Relações Internacionais. Trabalho de conclusão do curso de Graduação de Relações Internacionais da Faculdade de Ciências Econômicas da UFRG. Porto Alegre: UFRGS, 2014. 